\title{
Acquired Colonic Atresia in a Six-Week-Old Infant
}

\author{
Lalit Parida ${ }^{1} \mathbb{C}$
}

Received: 16 November 2021 / Accepted: 10 December 2021 / Published online: 2 February 2022

(c) Dr. K C Chaudhuri Foundation 2022

To the Editor: Colonic atresia is an uncommon type of congenital bowel atresia and usually presents in the first week of life. Acquired colonic atresia has been previously described in four patients with necrotizing enterocolitis (NEC), but all had surgical procedures done for it with subsequent development of colonic atresia [1].

Born at another medical facility, a male neonate of 35 wk gestational age received intravenous antibiotics and ranitidine in view of clinical sepsis. After discharge on day of life (DOL) 7, the baby was passing stool without any difficulty during the initial first few weeks of life. The baby was evaluated on DOL 34 for fever and an echocardiogram showed atrial and ventricular septal defects. The baby was started on oral furosemide which continued for $1 \mathrm{wk}$. The baby was admitted to the same external facility on DOL 41 due to intestinal obstruction and received intravenous antibiotics and ranitidine. He was referred to the authors' facility on DOL 44 with a grossly distended abdomen and absolute constipation. Laparotomy revealed colonic atresia and colostomies were done. Histopathological examination of the colonic segments was suggestive of NEC [2].

We presumed the risk factors of prematurity, antibioticinduced intestinal dysbiosis, and ranitidine to be associated with the development of NEC at around $5 \mathrm{wk}$ of life, and it was during this period when furosemide was introduced [3]. Loop diuretics like furosemide do not increase the risk of development of NEC, but on diagnosis of NEC may be associated with the progression of its severity from medical NEC to surgical NEC [4]. Late-onset NEC can develop in patients with described risk factors which can uncommonly then rapidly progress to colonic stricture and even atresia. To the best of our knowledge, this is the first reported case of NEC directly presenting as colonic atresia.

\section{Declarations}

Consent for Publication Informed consent for publication was obtained from the patient's father.

Conflict of Interest None.

\section{References}

1. Mares AJ, Freud E, Efrati Y, Bar-Ziv J, Maor E. Acquired colonic atresia: a rare sequela of necrotizing enterocolitis. J Pediatr Gastroenterol Nutr. 1993;16:93-7.

2. Ballance WA, Dahms BB, Shenker N, Kliegman RM. Pathology of neonatal necrotizing enterocolitis: a ten-year experience. $J$ Pediatr. 1990;117:S6-13.

3. Terrin G, Passariello A, De Curtis M, et al. Ranitidine is associated with infections, necrotizing enterocolitis, and fatal outcome in newborns. Pediatrics. 2012;129:e40-5.

4. Cole MA, DeRienzo C, Kutchibhatla M, Cotten CM, Adibe OO. Necrotizing enterocolitis and the use of loop diuretics in very low birth weight neonates. Am J Surg. 2016;211:645-8.

Publisher's Note Springer Nature remains neutral with regard to jurisdictional claims in published maps and institutional affiliations.

Lalit Parida

drlalitparida@yahoo.co.in

1 Department of Pediatric Surgery, Institute of Medical

Sciences \& SUM Hospital, Siksha 'O' Anusandhan

University, Bhubaneswar, Odisha 751003, India 